\title{
EXPERIMENTAL AND 3D NON-LINEAR STRESS ANALYSIS OF ADHESIVELY BONDED CURVED AND SCARF LAP JOINTS
}

\author{
ŞERIF ÇITIL \\ Adryaman University, Department of Mechanical Engineering, Adryaman, Turkey \\ e-mail: scitil@adiyaman.edu.tr
}

\begin{abstract}
Adhesive bonding is an excellent alternative to traditional joining techniques such as welding, riveting, and is commonly used in almost every sector of the industry. However, there are many factors that have to be accounted for during joint design to accurately predict strength of the joint. One of these is the design of adhesively bonded joints. The objective of this work is to study the influence of curvature on strength of adhesively bonded curved-lap joints. For that, different radii of curvature were introduced to the end zones of an aluminium sheet to which the adhesive is applied. Then, a scarf lap joint was obtained by increasing the radius of curvature for the same overlap length, and mechanical behaviour of curved and scarf lap joints was studied experimentally. Additionally, in the analyses, the Extended Drucker-Prager material model was used and to verify the finite element model, experiments were carried out. The results show that thickness, overlap length and curvature radius of the adherends have considerable influence on failure loads.
\end{abstract}

Keywords: adhesive, curvature radius, curved lap joint, finite element method, scarf lap joint

\section{Introduction}

Adhesively bonded joints have been commonly used in almost every sector of the industry, e.g., automotive, marine industry, space and aeronautics, as they offer significant advantages in applications. Different approaches were employed in the past to predict mechanical behaviour of bonded assemblies. In the early stages of analysis of bonded structures, theoretical studies were popular (Hart-Smith, 1973; Pirvics, 1974), which employed simplified assumptions in the structures geometry, materials behaviour, loading, and boundary conditions to formulate efficient closed-form elasticity solutions for local fields in the adhesive region. It is important to choose an appropriate approach for the analytical solution. The predictions based upon a modified von Mises yield criterion were compared with experimental results and experimental and numerical results were observed to be compatible with each other (Witney and Andrews, 1967; Raghava and Caddell, 1973). Also, the main advantage of analytical modelling is that the structure can be analyzed quickly, although with lots of embedded simplifications (Panigrahi and Pradhan, 2007). The substantial reduction in weight that can be achieved by using adhesive bonding is another important advantage, especially for lightweight structures (Adin, 2012).

Strength of bonded joints depends on many factors, such as type of the joint, geometric parameters, adherend materials and adhesive characteristics. Although its geometry is rather simple, stress distributions in peel and shear are highly complex. Joint analysis and strength prediction are often conducted by analytical or numerical (Finite Element, FE) methods (Domingues et al., 2016). Apart from the single-lap joint configuration, many other geometries have been studied in the literature such as double-lap, butt, corner, tubular, scarf, T-joints (di Bella et al., 2010; Çitil et al., 2017).

In isotropic or composite structures when high strength recovery is needed, or when there is a requirement for a flush surface to satisfy aerodynamic or stealth requirements, a bonded scarf 
or stepped repair is used (Gunnion and Herszberg, 2006). In the literature, although there are lots of works about scarf lap joints other than lap joints, there are not many works about curved lap joints. Therefore, in single lap joints with the flush surface and when especially curvilinear constructions are necessary, curved lap joints require investigation of mechanical properties. This work is particularly focused on situations where curvilinear parts must be assembled due to structural obligation.

No doubt, one of the most important advantages of adhesives is that they can easily combine the most difficult joint configurations. In adhesively bonded joints, surface geometry of the joint has a significant effect on the strength. Among many factors affecting strength of a bonded joint, stresses in both the adhesive layer and the adherends are most likely to be the most crucial in the design of bonded joints (Adams et al., 1997). Therefore, it is important to select an appropriate joint type in bonded joints. In today's technologies, it is possible to obtain different geometric models on surfaces of adherends with the same overlap length and thickness. The purpose of this work is to study the influence of curvature radius on strength of adhesively bonded curved-lap joints. For that, different curvature radii were made on the surface of an aluminum sheet. Then, a scarf lap joint was obtained by increasing the radius of curvature for the same overlap length, and mechanical behaviour of this curved and scarf lap joints was studied experimentally and 3D numerically. Various parameters such as adherend thickness, overlap length and curvature radius were investigated, and the effects of these parameters on strength of adhesively bonded joints were showed.

\section{Experimental investigation}

Aluminium alloy 2024-T3, which is widely used in the aviation field as the fastener, was used in this study. A two-component structural adhesive (DP410) produced by the $3 \mathrm{M}$ company was used as the joining element. Four bulk samples prepared to achieve the parameters needed to be defined for the Drucker-Prager model were obtained by being tensed in a tensile testing device at a tensile speed of $1 \mathrm{~mm} / \mathrm{min}$ at room temperature. Finally, the exponent Drucker-Prager (Raghava) material constants $(\lambda, \alpha, \psi, \sigma, \tau)$ for DP410 are given in Table 1 and Fig. 1b, where $\lambda, \alpha, \psi, \sigma$ and $\tau$ show, respectively, the hydrostatic stress sensitivity parameter, pressure sensitivity parameter associated with hydrostatic stress, the dilatation angle, tensile and shear stress-shear. Furthermore, these parameters $(\lambda, \alpha, \psi)$ are detailed in Section 3.1.

Table 1. Material parameters for the exponent Drucker-Prager model (DP410)

\begin{tabular}{|c|c|c|c|c|c|}
\hline$E[\mathrm{MPa}]$ & $\lambda$ & $\alpha[\mathrm{MPa}]$ & $\nu_{p}$ & $\tan \psi$ & $\sigma, \tau$ \\
\hline \hline 2283 & 1.14 & 16.9 & 0.44 & 0.125 & see Fig. 1 \\
\hline
\end{tabular}

(a)

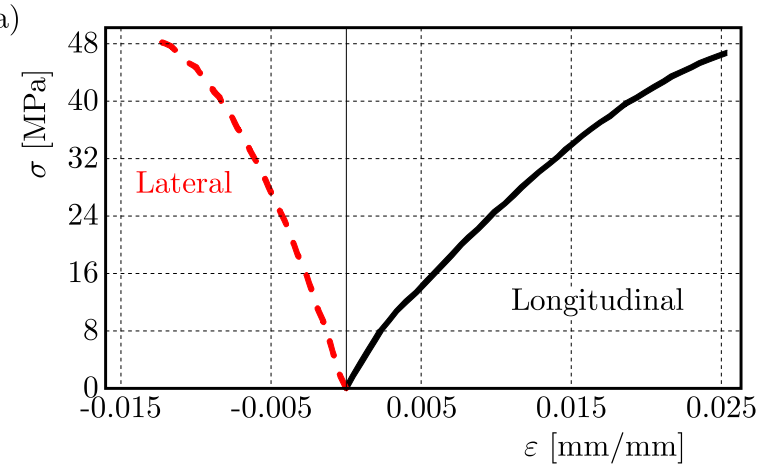

(b)

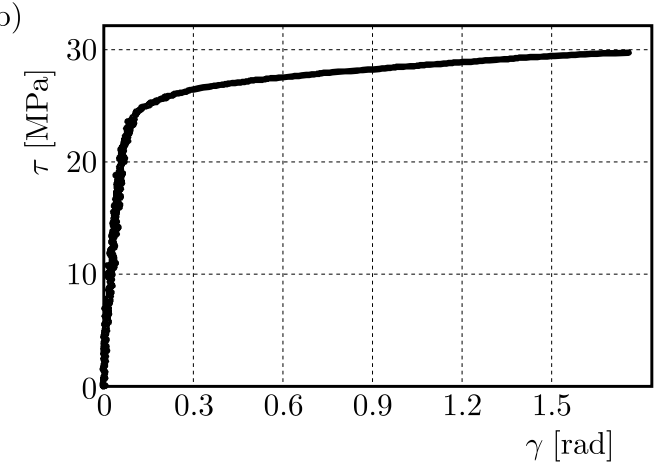

Fig. 1. (a) Lateral stress-strain and longitudinal (tensile) stress-strain behaviour of adhesive (DP410). (b) Shear stress-shear strain behaviour of DP410 
Thick-adherend shear (TAS) tests were used for shear stress-shear strain behaviour of DP410. Also, mechanical properties of AA2024-T3 were used as adherends in numerical simulations, see Table 2 (Çitil et al., 2011). Lateral stress-strain, longitudinal (tensile) stress-strain and shear stress-strain behaviour of adhesive (DP410) were obtained from uniaxial loading conditions by using a video extensometer.

\subsection{Joint configuration and production}

In this study, the effects of radius of curvature on strength were investigated in inclined-surface overlapping joints. For this purpose, two types (Type I, Type II) of connection models were created for thicknesses of $h=6.5 \mathrm{~mm}$ with overlapping lengths of $l=25,30 \mathrm{~mm}$, respectively (Fig. 2). Curvilinear surfaces with $r=100,300$ and $500 \mathrm{~mm}$ radius, respectively, were formed to Type I connection model so that its radius would increase by $200 \mathrm{~mm} . r_{1}$ and $r_{2}$ radius were produced depending on the radius of curvature $(r)$ to obtain adhesive thickness $(t=0.2 \mathrm{~mm})$ between the parts to be joined. As the radius of curvature of the surfaces to be joined with the adhesive was increased. Type II model with a scarf joint was created in accordance with this increased planarity (Fig. 3).

Table 2. Material parameters of adherend (AA 2024-T3)

\begin{tabular}{|l|c|}
\hline Properties & Materials (AA 2024-T3) \\
\hline \hline Young's modulus $E[\mathrm{MPa}]$ & 71875 \\
\hline Poisson's ratio $\nu$ & 0.33 \\
\hline Ultimate tensile strength $\sigma_{t}[\mathrm{MPa}]$ & 481.9 \\
\hline Ultimate tensile strain $\varepsilon_{t}$ & 0.1587 \\
\hline
\end{tabular}

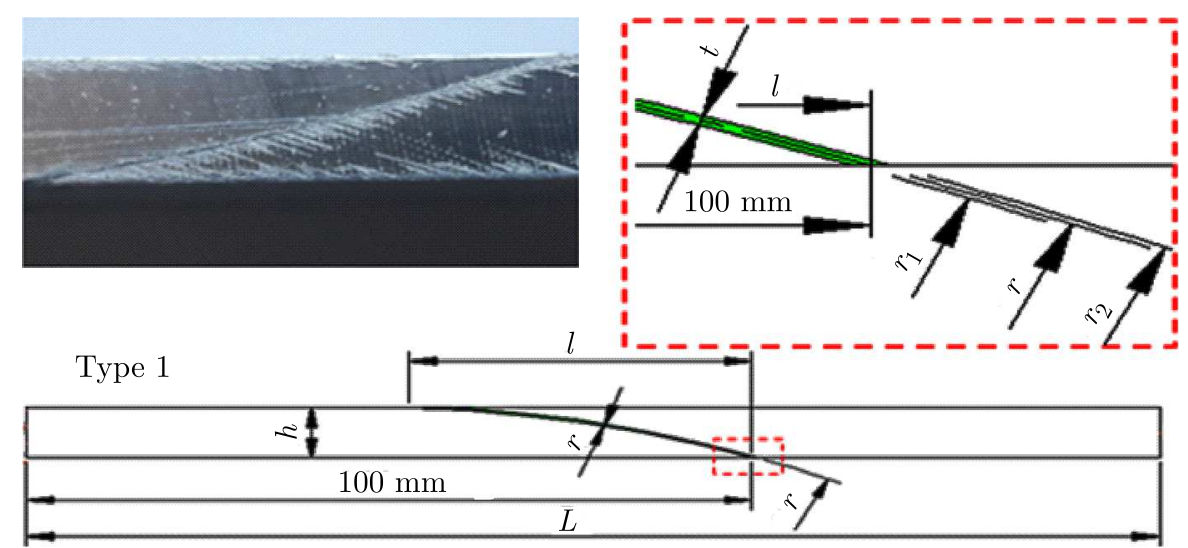

Fig. 2. Geometric parameters of the curved lap joint (Type I)

To verify the finite element model, experiments were carried out. It was necessary to remove substances such as paint, oil and dust on the surface to obtain good adhesion between the adhesive and the part surface in joint elements. Aluminium adherends were bonded with the DP410 two-constituent (2/1 mixing ratio) acrylic structural liquid adhesive (3M Scotch-Weld), which is resistant to humidity, and the bonding was achieved by curing at room temperature in a hydraulic press under $0.1 \mathrm{MPa}$ pressure for a day. Three samples of each joint type were produced. In addition, the mold shown in Fig. 4 was used in production of samples to fix the position of the adherends to adjust thickness of the adhesive layer and to apply a uniform pressure. In order to obtain an adhesive layer thickness of $t=0.2 \mathrm{~mm}$ after curing, the adherends were placed into the mold. When the adherends were joined with the adhesive, the total length $L$ is $175 \mathrm{~mm}$ for overlap length $25 \mathrm{~mm}$ and was $170 \mathrm{~mm}$ for overlap length $30 \mathrm{~mm}$ (Fig. 4). 


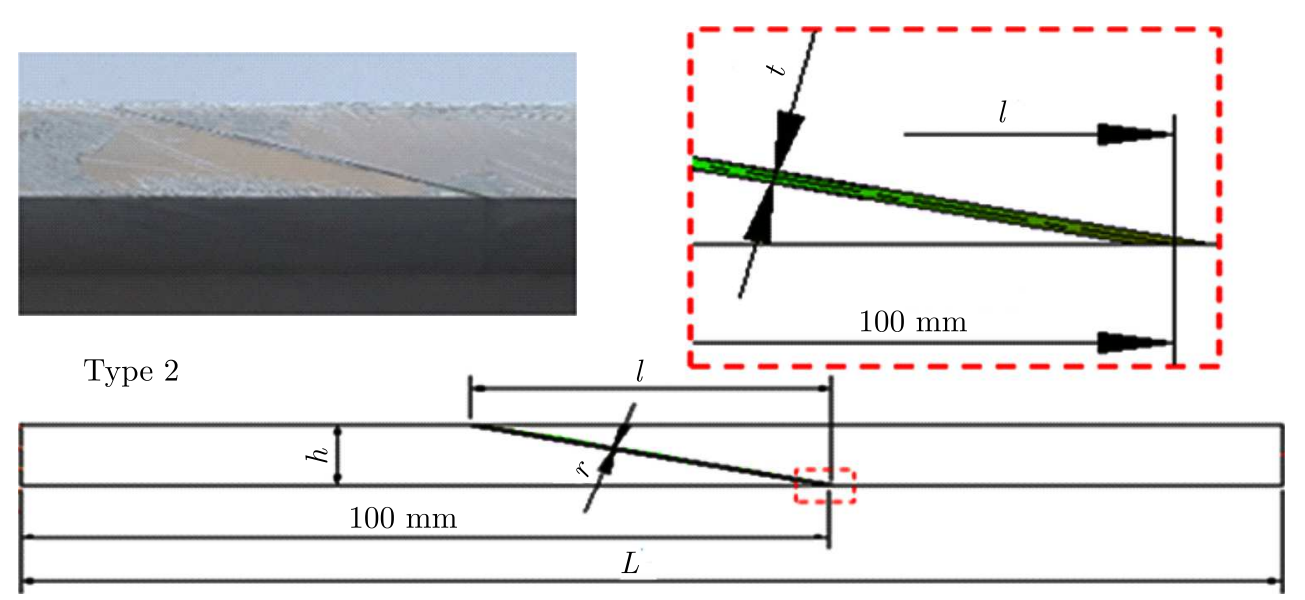

Fig. 3. Geometric parameters of the scarf lap joint (Type II)

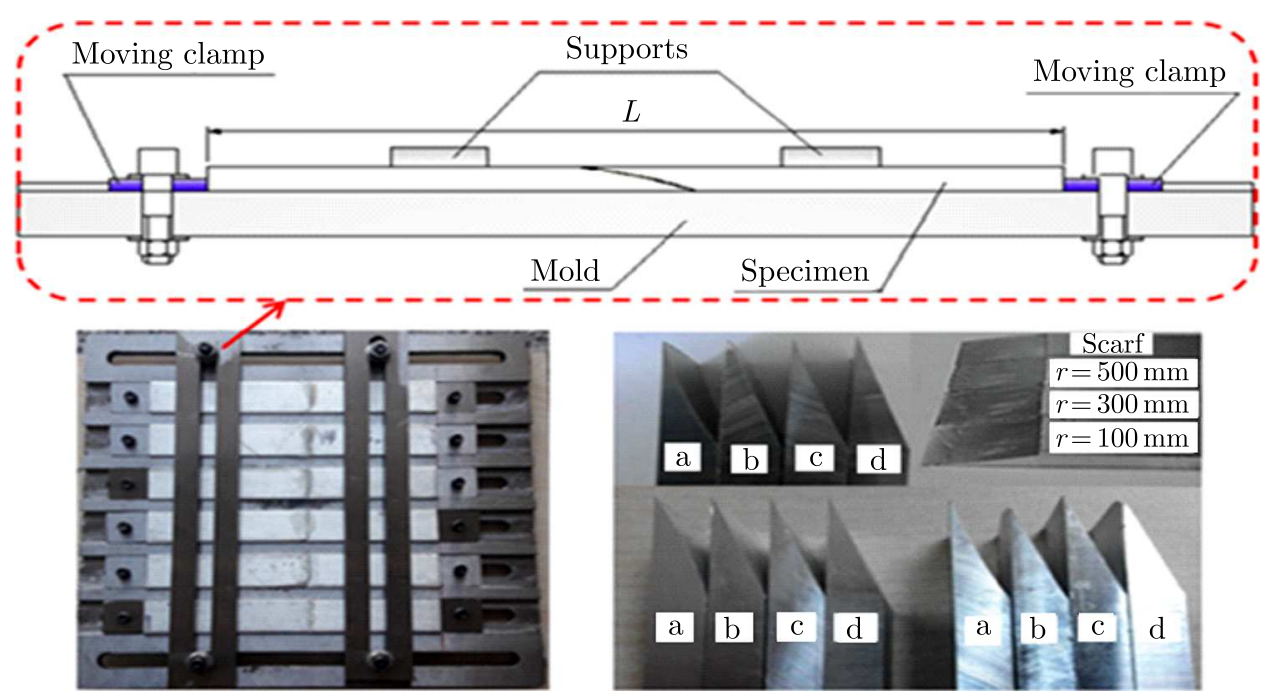

Fig. 4. The mold used in preparation of the specimens

\subsection{Experimental method}

The test specimens were produced to have a thickness of $h=6.5 \mathrm{~mm}$ and an overlapping length of $l=25,30 \mathrm{~mm}$. Furthermore, three curvilinear and three angled overlapping joints were created to have a radius of $r=100,300,500 \mathrm{~mm}$, respectively, for each overlapping length (Fig. 4b). All experiments were conducted by a tensile testing machine with a $100 \mathrm{kN}$ load cell, under $1 \mathrm{~mm} / \mathrm{min}$ crosshead speed, in a laboratory with $24^{\circ} \mathrm{C}$ temperature and in $35 \%$ humid environment one week after production of the specimens (Fig. 4a). Experimental results are presented graphically in Table 4.

\section{Numerical modelling}

In this study, a non-linear finite element model was developed in the ANSYS 15 by considering both geometrical non-linearity and non-linear material behaviours of the adhesive (DP410) and aluminium alloy (AA 2024-T3) given in Fig. 1, Table 1 and Table 2. The geometric parameters (Figs. 2 and 3), loading and boundary conditions used in the finite element analyses were the same as those used in the experimental study (Fig. 5). In the finite element analysis, the model was fixed $\left(U_{x}=0, U_{y}=0\right.$ and $U_{z}=0$ ) for the displacements along the $x, y$ and $z$-axis in 
region $\mathrm{A}$. But in region $\mathrm{B}$, the model was fixed $\left(U_{x}=0\right.$ and $\left.U_{y}=0\right)$ for the displacements along the $x, y$. The load was applied along the $z$-axis. In 3D analysis, the created models were divided into finite elements using solid186 with 20 nodes. The critical regions associated with stress distributions were divided into smaller elements (Fig. 5). In addition, the mesh was evaluated using the skewness criterion in the ANSYS Workbench program and the mesh quality was 0.68. According to the skewness criteria, a good mesh is in the range of 0.5-0.8 (www.academia.edu).

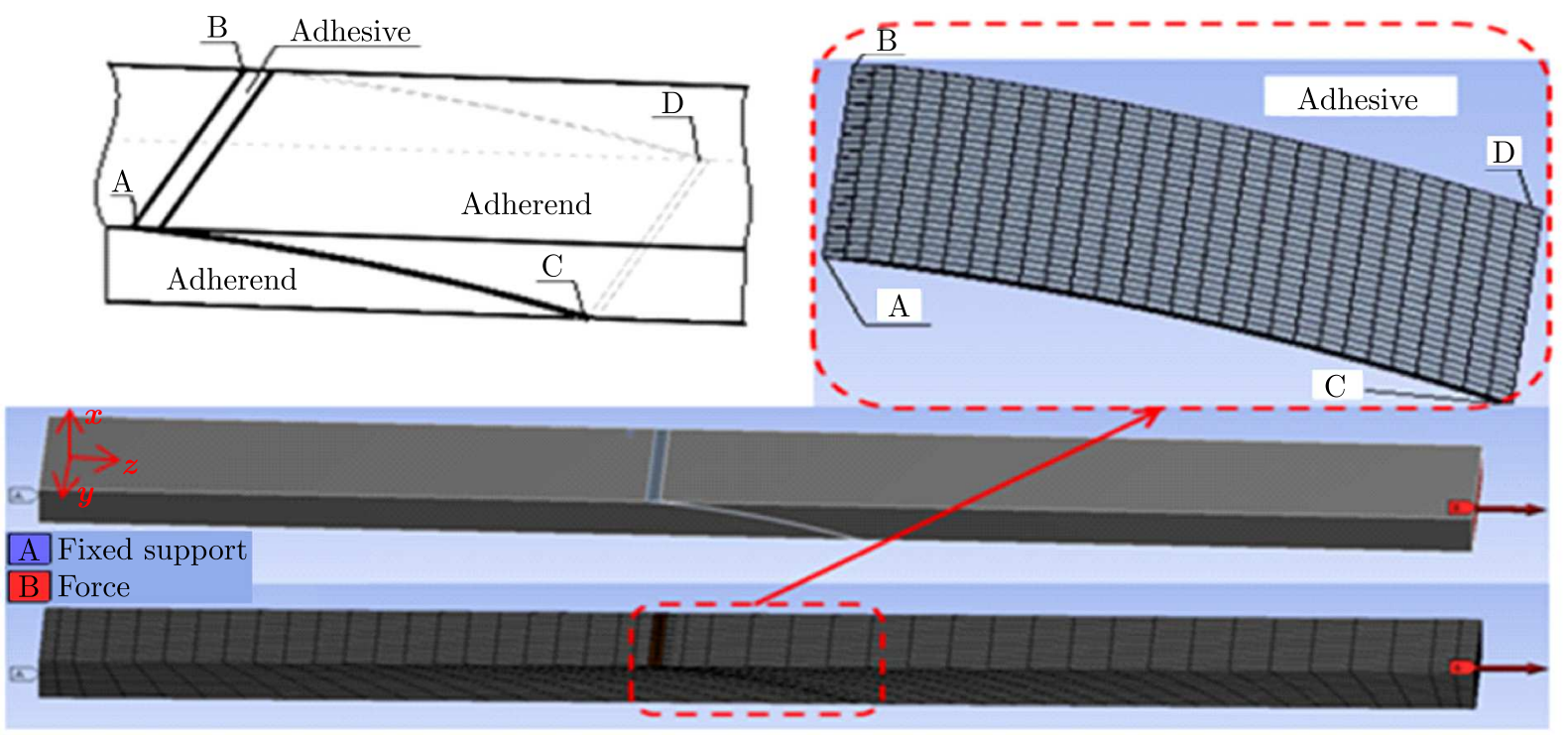

Fig. 5. Boundary conditions and ABCD surface used in 3D numerical studies

Moreover, the mesh density considering stress singularities at the interface can affect stress predictions in the adhesive layer. A smaller element size generally gives a higher maximum strain. For this reason, the mesh size was kept constant in all models (Işcan and Adin, 2012). Numerical failure load results are given in Table 3.

The adhesive used exhibits a non-linear relationship between stress and strain. For the purpose of finite element analysis, elastic-plastic models have been used to describe the deformation behaviour. The Raghava criterion was used in the three-dimensional stress analysis of the lap joints subjected to tensile load (Aydin et al., 2007; Aydin, 2008; Raghava et al., 1973)

$$
\left(\sigma_{2}-\sigma_{3}\right)^{2}+\left(\sigma_{3}-\sigma_{1}\right)^{2}+2\left(\sigma_{c}-\sigma_{t}\right)\left(\sigma_{1}+\sigma_{2}+\sigma_{3}\right)=2 \sigma_{c} \sigma_{t}
$$

where $\sigma_{1}, \sigma_{2}$ and $\sigma_{3}$ represent the principal stresses causing yield, $\sigma_{c}$ and $\sigma_{t}$ are the absolute values of uniaxial compressive and tensile yield stresses of the adhesive material, respectively. Equation (3.1) can be written in a different form as it is shown below (Charalambides and Olusanya, 1997; Dean and Duncan, 1995; Read et al., 2000)

$$
\begin{aligned}
& \frac{q^{2}}{\lambda \sigma_{t}^{2}}+\frac{3 \sigma_{t}(\lambda-1) \sigma_{m}}{\lambda \sigma_{t}^{2}}=e \begin{cases}e \geqslant 1 & \text { failure } \\
e>1 & \text { no failure }\end{cases} \\
& q^{2}=\frac{1}{2}\left[\left(\sigma_{1}-\sigma_{2}\right)^{2}+\left(\sigma_{2}-\sigma_{3}\right)^{2}+\left(\sigma_{3}-\sigma_{1}\right)^{2}\right]=3 J_{2} \\
& \sigma_{m}=\frac{J_{1}}{3}
\end{aligned}
$$

where $J_{1}, J_{2}$ and $q$ are the first invariant of the stress tensor, the second invariant of the deviatoric stress tensor and the von Mises equivalent stress, respectively. $\sigma_{m}$ represents the average stress or hydrostatic stress, and $e$ is the damage index 


$$
\lambda=\frac{\sigma_{c}}{\sigma_{t}} \quad \lambda=\frac{\sigma_{c}^{2}}{3 \tau_{y}^{2}} \quad \lambda=\frac{3 \tau_{y}^{2}}{\sigma_{t}^{2}}
$$

Here, $\lambda, \sigma_{t}$ (compressive), $\sigma_{c}$ (tensile) and $\tau_{y}$ (shear) are the hydrostatic stress sensitivity parameters associated with shear-yield stress (3.3). Equation $(3.2)_{1}$ is included in the ANSYS (version 15) package program (ANSYS, 2015) and is represented as given below (Drucker and Prager, 1952)

$$
q^{2}+\alpha \sigma_{m}=\sigma_{t}^{b}
$$

Here, $\alpha$ and $b$ are the pressure sensitivity parameter associated with hydrostatic stress and the material parameter characterizing shape of the flow surface, respectively. If Eqs. (3.2) and (3.4) are written together and rearranged by taking $b=2$, the following equation is derived for $\alpha$

$$
\alpha=3 \sigma_{t}(\lambda-1)
$$

Furthermore, $E_{a}, \nu_{e}, \alpha, \psi$ are parameters that need to be defined for the exponent Drucker-Prager model. $\psi$ shows the dilatation angle. The dilatation angle is calculated as follows

$$
\tan \psi=\frac{3\left(1-2 \nu_{p}\right.}{2\left(1+2 \nu_{p}\right)}
$$

\section{Numerical solutions}

In the FE studies, two different models were simulated. The joint considered in this study and the boundary conditions are represented in Fig. 5. In the analysis, the material non-linearity based on the uniaxial stress-strain behaviour of the adhesive (DP410) and adherend (AA 2024-T3) was taken into consideration (Fig. 1, Tables 1 and 2). The geometrical parameters used in the FE analysis are given in Figs. 2 and 3.

When the joint models created are subjected to tensile load, there is a triaxial stress state on the adhesive layer. For this reason, the equivalent stresses $\sigma_{e q}$ were calculated according to the Drucker-Prager yield criterion given in Eq. (3.2). It has been assumed that damage occurs when the equivalent stress reaches the tensile strength $\sigma_{t}$ of the adhesive at any point of the adhesive layer.

Table 3. Numerical damage load results

\begin{tabular}{|c|c|c|c|c|}
\hline \multicolumn{5}{|c|}{ Numerical tensile failure load values $[\mathrm{kN}]$} \\
\hline Overlap length $l[\mathrm{~mm}]$ & $r[\mathrm{~mm}]$ & $h=6.5 \mathrm{~mm}$ & $h=10 \mathrm{~mm}$ & $h=13.5 \mathrm{~mm}$ \\
\hline \hline \multirow{3}{*}{20} & 100 & 13.6 & 15.6 & 19 \\
\cline { 2 - 5 } & 300 & 13.8 & 16.4 & 19.2 \\
\cline { 2 - 5 } & 500 & 14.4 & 16.4 & 19.4 \\
\cline { 2 - 5 } & scarf & 14.6 & 16.7 & 19.6 \\
\hline \multirow{5}{*}{25} & 100 & 14 & 17.2 & 19.6 \\
\cline { 2 - 5 } & 300 & 16.8 & 18 & 20.5 \\
\cline { 2 - 5 } & 500 & 17.2 & 18.5 & 21 \\
\cline { 2 - 5 } & scarf & 18 & 19.6 & 21.4 \\
\hline \multirow{5}{*}{30} & 100 & 17 & 18 & 21 \\
\cline { 2 - 5 } & 300 & 18.4 & 21 & 22 \\
\cline { 2 - 5 } & 500 & 18.4 & 21.2 & 23 \\
\cline { 2 - 5 } & scarf & 21 & 21.6 & 24 \\
\hline
\end{tabular}


When the connection models were examined, as the radius of curvature of the inclined model increased, the arc length of the connection decreased and became linear. Furthermore, as the radius of curvature increased in the inclined connection model with the same overlapping length and thickness, the arc length of the radius of curvature and surface area of connection model decreased (Fig. 7) and the scarf connection model Type II was formed.

When Table 3 is examined, it is observed that there is a significant increase in the load-carrying capacity as the overlap length and adherend thickness of the same models increase. It is clearly observed that this is due to the increase in the area of the surface on which the adhesive is applied. When we compared the joint models with the same overlap length and thickness among themselves for $r=100,300,500 \mathrm{~mm}$ and scarf, there was also an increase in the damage loads brought about by them. However, there is a decrease in the surface areas of the joints due to the increase in the radius. When they are examined respectively, the surface area for $100 \mathrm{~mm}$ radius was $661.33 \mathrm{~mm}^{2}$, the surface area for $300 \mathrm{~mm}$ radius was $649.29 \mathrm{~mm}^{2}$, the surface area for $500 \mathrm{~mm}$ radius was $648.14 \mathrm{~mm}^{2}$ and the surface area for the scarf was $645.78 \mathrm{~mm}^{2}$ (Fig. 6).

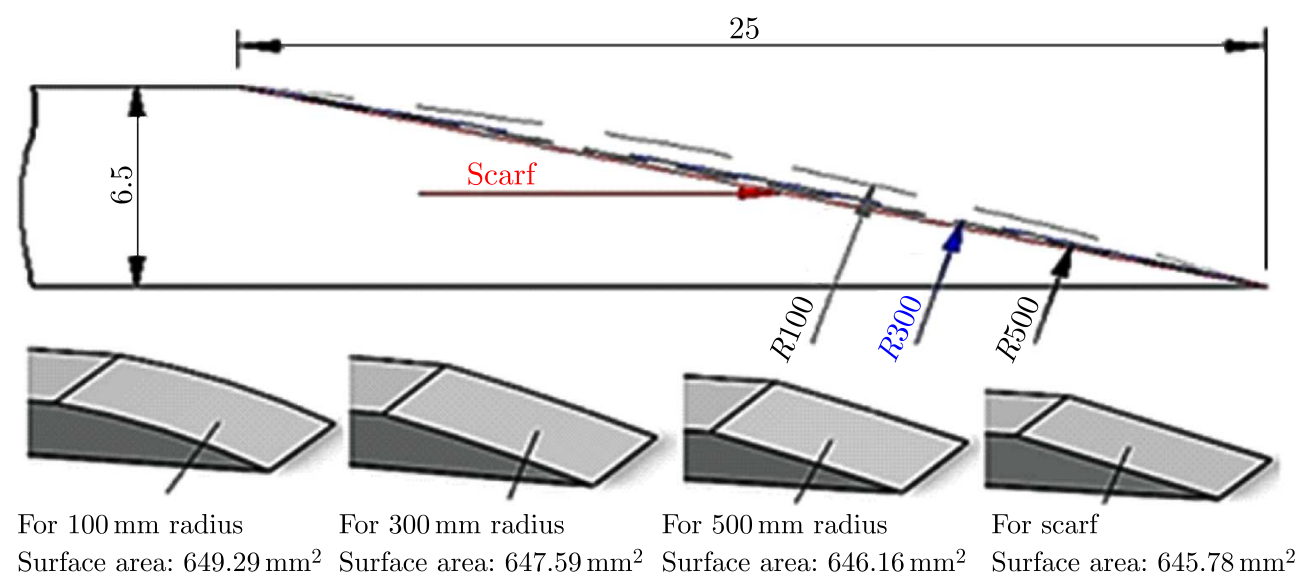

Fig. 6. Surface area of overlapping joints depending on the radius increase

In this case, the scarf joint model is expected to carry the lowest load, and the model with a radius of $100 \mathrm{~mm}$ is expected to carry the largest load. Here, there is a reverse situation. The reason for this situation is that the peel stress tendency occurring on the joint surface increased as the radius of the joint decreased.

\section{Experimental results}

The test specimens with $h=6.5 \mathrm{~mm}$ thickness and $l=25,30 \mathrm{~mm}$ overlap lengths were tested for $r=100,300,500 \mathrm{~mm}$, The simulation findings for the scarf overlapping joint and experimental results are given in Table 4 . The mean experimental results obtained were compared with the results obtained with the finite elements. As a result of the comparison made, it was shown that the results obtained with the finite elements were compatible with the test results by $86 \%$ (Table 4 ). They were shown incompatible by about $14 \%$ in experimental and numerical analysis results. This percentage difference is due to the method of surface preparation, heating-cooling rate, pressure applied during the coupling, recrystallization process when preparing the adhesive joints (Lapique and Redford, 2002; Adams et al., 1992). The tensile testing machine obtained load-deformation curves are presented graphically in Fig. 7.

Figure $8 \mathrm{~b}$ shows the damage load results obtained from the tensile test device. The greatest damage load was obtained for the scarf lap joint while the lowest damage load was obtained for the $r=100 \mathrm{~mm}$ curved lap joint. 
Table 4. Numerical and experimental damage loads

\begin{tabular}{|c|c|c|c|c|c|}
\hline \multirow{2}{*}{$r[\mathrm{~mm}]$} & $h[\mathrm{~mm}]$ & $l[\mathrm{~mm}]$ & $\begin{array}{c}\text { Num. tensile } \\
\text { failure load } \\
{[\mathrm{kN}]}\end{array}$ & $\begin{array}{c}\text { Exp. tensile } \\
\text { failure load } \\
{[\mathrm{kN}]}\end{array}$ & FFEM/FEXP \\
\hline \hline \multirow{2}{*}{100} & 6.5 & 25 & 14 & 14.33 & 0.97 \\
\cline { 2 - 6 } & 6.5 & 30 & 17 & 18.42 & 0.92 \\
\hline \multirow{2}{*}{300} & 6.5 & 25 & 16.8 & 20.37 & 0.82 \\
\cline { 2 - 6 } & 6.5 & 30 & 18.4 & 21.62 & 0.85 \\
\hline \multirow{2}{*}{500} & 6.5 & 25 & 17.2 & 20.36 & 0.84 \\
\cline { 2 - 6 } & 6.5 & 30 & 18.4 & 22.12 & 0.83 \\
\hline \multirow{2}{*}{ scarf } & 6.5 & 25 & 18 & 22.77 & 0.79 \\
\cline { 2 - 6 } & 6.5 & 30 & 21 & 23.49 & 0.89 \\
\hline
\end{tabular}

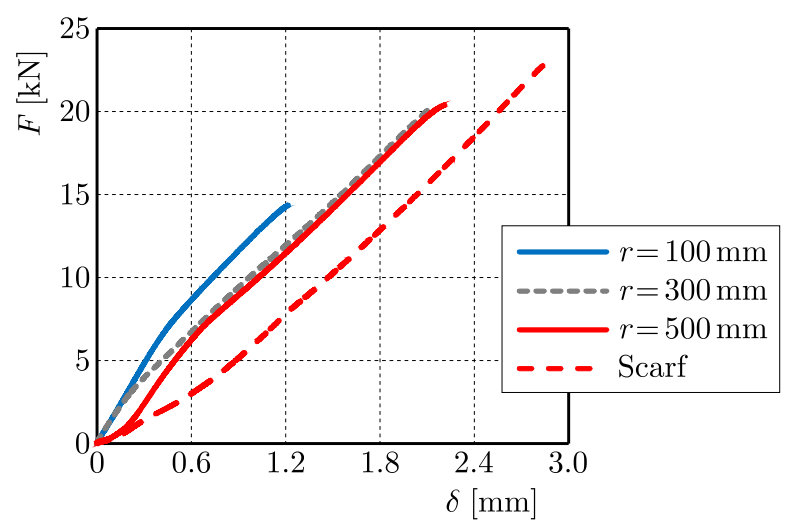

Fig. 7. Experimental damage loads for $25 \mathrm{~mm}$ overlapping length

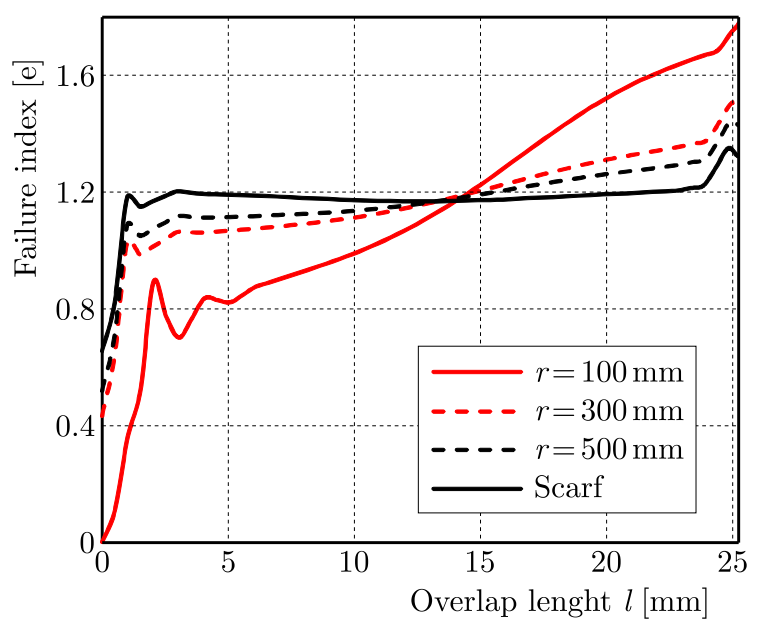

Fig. 8. The distribution of the damage index along AC line

In Fig. 8, the damage index in the adhesive layer is calculated. The damage index $e$ is a parameter defined to estimate the strength of the joint. The damage index of the adhesive must be $e<1$ to avoid damage. If the damage index is $e \geqslant 1$, it means that damage has occurred. The distribution of the damage index along the overlap length of the adhesive (along the AC line) is given in Fig. 5. As it can be understood from this figure, the lowest damage index was formed in the scarf joint model, and the highest damage index occurred in the $r=100 \mathrm{~mm}$ curvilinear lap joint. The damage index occurred along the $\mathrm{AC}$ line, especially in the region where the point $\mathrm{C}$ is located. It means that the damage starts in the region where the point $\mathrm{C}$ is located. 


\section{Conclusions}

In this study, the scarf lap joint was formed by increasing the radius of curvature in curvilinear surface lap joints and by making a curvilinear surface plane, and then it was subjected to tensile load. The damage index of curvilinear (Type-I) and scarf (Type-II) lap joints under tensile load were found by a three-dimensional non-linear finite element analysis. Experimental tests were performed to verify the non-linear finite element analysis. As a result, experimental and numerical results were observed to be compatible by $86 \%$. As the radius of curvature of the curvilinear surface lap joint increased, the arc length of the curve decreased and the area of the surface on which the adhesive was applied decreased. However, the damage load carried by them increased. The highest damage load was carried by the scarf joint model. The lowest damage index was formed in the scarf joint model, and the highest damage index occurred in the $r=100 \mathrm{~mm}$ curvilinear lap joint. When the overlap length and adherend thickness of the same models was increased, the area of the surface on which the adhesive was applied increased and the damage load carried by them increased as well.

\section{References}

1. Adams R.D., Comyn J., Wake W.C., 1997, Structural Adhesive Joints in Engineering, Elsevier, Amsterdam

2. Adams R.D., Coppendale J., Mallick V., Al-Hamdan H., 1992, The effect of temperature on the strength of adhesive joints, International Journal of Adhesion and Adhesives, 12, 3, 185-190

3. Adin H., 2012, The investigation of the effect of angle on the failure load and strength of scarf lap joints, International Journal of Mechanical Sciences, 61, 24-31

4. ANSYS Workbench, version 15, 2015, Swanson Analysis Systems, Inc., Houston, Texas

5. Aydin M.D., 2008, 3-D nonlinear stress analysis on adhesively bonded single lap composite joints with different ply stacking sequences, The Journal of Adhesion, 84, 15-36

6. Aydin M.D., Temiz Ş., Özel A., 2007, Effect of curing pressure on the strength of adhesively bonded joints, The Journal of Adhesion, 83, 553-571

7. Charalambides M.N., Olusanya A., 1997, NPL CMMT(B)130, National Physical Laboratory, Teddington, UK

8. Çıtıl Ş., Ayaz Y., Temiz Ş., 2017, Stress analysis of adhesively bonded double strap joints with or without intermediate part subjected to tensile loading, The Journal of Adhesion, 93, 5, 343-356

9. Çıtıl Ş., Temiz Ş., Altun H., Özel A., 2011, Determination of mechanical properties of doublestrap adhesive joints with an embedded patch, Journal of Adhesion Science and Technology, 25, $18,2555-2567$

10. Dean G.D., Duncan B.C., 1995, NPL Report DMM(B) 448, National Physical Laboratory, Teddington, Middlesex, UK

11. Dean G.D., Crocker L., Read B., Wright L., 2004, Prediction of deformation and failure of rubber-toughened adhesive joints, International Journal of Adhesion and Adhesives, 24, 295-306

12. Di Bella G., Borsellino C., Pollicino E., Ruisi V.F., 2010, Experimental and numerical study of composite T-joints for marine application, International Journal of Adhesion and Adhesives, 30, 347-358

13. Domingues N.R.E., Campilho R.D.S.G., Carbas R.J.C., Da Silva L.F.M., 2016, Experimental and numerical failure analysis of aluminium/composite single- $L$ joints, International Journal of Adhesion and Adhesives, 64, 86-96

14. Drucker D.C., Prager W., 1952, Soil mechanics and plastic analysis for limit design, Quarterly of Applied Mathematics, 10, 157-165 
15. Gunnion A.J., Herszberg I., 2006, Parametric study of scarf joints in composite structures, Composite Structures, 75, 364-376

16. Hart-Smith L.J., 1973, Adhesive-bonded single-lap joints, NASA Technical Report CR- 112236. Hampton, USA: Langley Research Centre

17. https://www.academia.edu/16970000/mesh_quality_and_advenced_topics_ansys_workbench_16.0 (accessed 12 February 2015)

18. IŞCAN B., AdIN H., 2012a, The influence of adherend width on tensile strength and failure load of Z joints bonded with adhesive, International Journal of Physical Sciences, 7, 41, 5598-5606

19. LApique F., Redford K., 2002, Curing effects on viscosity and mechanical properties of a commercial epoxy resin adhesive, International Journal of Adhesion and Adhesives, 22, 4, 337-346

20. Panigrahi S., Pradhan B., 2007, Three dimensional failure analysis and damage propagation behavior of adhesively bonded single lap joints in laminated FRP composites, Journal of Reinforced Plastics and Composites, 26, 183-201

21. Pirvics J., 1974, Two dimensional displacement-stress distributions in adhesive bonded composite structures, The Journal of Adhesion, 6, 207-228

22. Raghava R.S., Caddell R.M., 1973, 1973, A macroscopic yield criterion for crystalline polymers, Journal of Materials Science, 15, 12, 967-974

23. Raghava R., Cadell R.M, Yeh G.S.Y., The macroscopic yield behaviour of polymers, Journal of Materials Science, 8, 2, 225-232

24. Read B.E., Dean G.D., Ferriss D.H., 2000, NPL CMMT(A) 289, National Physical Laboratory, Teddington, UK

25. Witney W., Andrews R.D., 1967, Yielding of glassy polymers: Volume effects, Journal of Polymer Science Part C, 16, 5, 2981-2990 